\title{
G

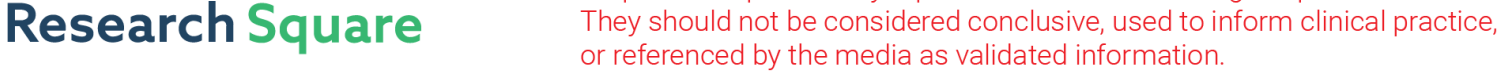 \\ PERSonality, Ehical, and PROfessional Quality of Life in Pediatric/Adult Intensive Nurses Study: PERSEPRO PAIN Study
}

\section{Yujiro Matsuishi}

University of Tsukuba

\section{Bryan Mathis}

University of Tsukuba

Haruhiko Hoshino

University of Tsukuba

Yuki Enomoto

University of Tsukuba

Nobutake Shimojo

University of Tsukuba

\section{Satoru Kawano}

University of Tsukuba

\section{Hideaki Sakuramoto}

Ibaraki Christian University

Yoshiaki Inoue ( $\nabla$ yinoue@md.tsukuba.ac.jp )

University of Tsukuba

\section{Research Article}

Keywords: Intensive Care Nursing, Intensive Care Nurses, Critical Care Nursing, Burnout syndrome

Posted Date: January 15th, 2021

DOI: https://doi.org/10.21203/rs.3.rs-144202/v1

License: (c) (1) This work is licensed under a Creative Commons Attribution 4.0 International License. Read Full License

Version of Record: A version of this preprint was published at PLOS ONE on March 7th, 2022. See the published version at https://doi.org/10.1371/journal.pone.0259721. 


\section{Abstract}

Background Burnout syndrome (BOS) is emotional exhaustion that reduces both professional quality of life (QOL) and satisfaction derived from work. The World Health Organization (WHO) included BOS criteria in its 11th Revision of the International Classification of Diseases (ICD-11) in 2019 and nursing bodies have issued calls to action to prevent BOS. Despite of this importance, the effect of social factors, personality traits and cross- interaction on professional QOL is still unclear.

Method An online survey whose enrollment criteria included registered nurses working in adult, pediatric or both ICUs. We used the ten-item personality measure (TIPI) and Type-D personality Scale-14 (DS14) then measured the ethical climate by using the Hospital Ethical Climate Survey (HECS) and the professional QOL domains BOS, secondary traumatic stress (STS), and compassion satisfaction (CS) by the Professional Quality of Life Scale Version 5 (Pro-QOL V) simultaneously. Multivariate analysis of factors, including demographic data and interaction terms, confirmed the triangle association of hospital ethical climate, personality traits and professional QOL.

Result We enrolled 310 participants from September 2019 to February 2020. Mean age was 33.1 years ( \pm 5.9 ) and about $70 \%$ were female. In the multivariate analysis, neuroticism $(p=0.03)$, Type $D$ personality $(p<0.01)$ were associated with BOS, and BOS-associated factors and agreeableness $(p<0.01)$ was associated with STS. On the other hand, extraversion $(p=0.01)$, agreeableness $(p<0.01)$ and openness $(p<0.01)$ were associated with CS. We also observed interactions between hospital ethical climate and conscientiousness $(p=0.01)$ for BOS and STS. neuroticism $(p<0.01)$ for BOS and CS, Type D personality $(p<0.01)$ for BOS and STS.

Conclusion Hospital ethical climate strongly affects the magnitude of professional QOL in nurses with specific personality traits. Therefore, it is important for management to maintain an ethical hospital climate and consider individual personalities to maintain professional QOL and prevent BOS.

\section{Introduction}

The term "burnout" was first used in nearly half a century ago by Freudenberger ${ }^{1}$ while Maslach defined burnout syndrome (BOS) by three symptoms: emotional exhaustion, depersonalization and reduced personal accomplishment ${ }^{2,3}$. The World Health Organization (WHO) included BOS criteria in its 11th Revision of the International Classification of Diseases (ICD-11) in $2019^{4}$ and the UK Health and Safety Executive (HSE) reported 15.4 million working days lost due to BOS in $2017-201^{5}$. BOS in the nursing fields, especially critical care, has been recognized by national societies such as the Critical Care Societies Collaborative (CCSC) and the American Association of Critical Care Nurses (AACN) with calls to action for BOS prevention ${ }^{6}$.

Working specialty plays a crucial role in burnout, an effect especially seen in pediatric intensive care ${ }^{7}$ and intensive care nurses ${ }^{8-10}$. These nurses have been reported to experience intense occupational stress in 
their daily work ${ }^{11}$ and, as observing death is a strong risk factor for BOS ${ }^{12}$, places where death is frequently observed, such as the intensive care unit, makes BOS prevention challenging. The result is that patient safety can be compromised as seen in a previous study which revealed that time pressure adversely affected patient safety for nurses with $\mathrm{BOS}^{13}$, an association confirmed by another study ${ }^{14}$. From these reasons, further studies on BOS in intensive care nurses are required and these studies benefit both nurses and patients. Previous studies have already confirmed that BOS is related to social factors such as work environment/climate, management ${ }^{15,16}$, and also specific personality factors ${ }^{17-22}$.

Recently, BOS has been classified as not merely psychological but also a domain of professional quality of life (QOL). Stamm et al defined professional QOL as the feeling resulting from the relationship between caregivers and patients that includes three domains: burnout (BOS), secondary traumatic stress (STS), and compassion satisfaction(CS) ${ }^{23}$.

The word "compassion" describes the sympathetic awareness of another's distress and STS is compassion fatigue defined as the emotional withdrawal experienced by caregivers of traumatized people. Although it may be an expected side effect of caregiving, nursing is still a high risk cohort for having STS in spite of efforts and training to prevent it ${ }^{24}$. Balancing STS is CS, which is a positive feeling of accomplishment gained through the caregiving profession. Nurses must constantly walk this tightrope between STS and CS and thus measurements of professional QOL ${ }^{23}$ must observe BOS, STS and CS simultaneously to analyze the balance between these three domains.

Even with an understanding of the association between BOS and its associated domains (STS and CS), associated factors for professional QOL are still unclear. A recent study revealed that lifestyle and demographic information were associated with a poor professional QOL ${ }^{25}$ but the impact and interaction of factors such as hospital ethical climate and personality traits on BOS is underreported.

Therefore, we hypothesize that:

1. The ethical climate of a hospital (hospital ethical climate; HEC) is an independent risk factor for professional QOL (BOS, STS and CS).

2. Specific personality traits are independent risk factors for professional QOL (BOS, STS and CS).

3. There are interactions between hospital ethical climate and specific personality traits for professional QOL, indicating that hospital ethical climate strongly affects professional QOL in nurses with specific personality traits.

\section{Methods}

\section{Participant selection}

We used an online survey to solicit participants and enrolled registered nurses working in adult, pediatric or hybrid ICUs from September 2019 to February 2020. The survey was distributed via the official laboratory social network services (SNS) account to recruit participants. Informed consent (via an online 
form) was taken before the online survey and ethical approval was obtained. We also distributed the survey to professional mailing lists consisting of Japanese intensive care nurses through a nonprofit organization called the Japanese Society of Education for Physicians and Trainees in Intensive Care (JSEPTIC). All surveys were conducted with Japanese domestic nurses.

\section{Demographic data}

We extracted characteristics, including age, sex, marital status, number of children, hobbies, exercise habits, annual income, academic degree, years of nursing experience, and years of ICU experience.

\section{Measurement of personality traits}

When choosing tools to assess personality traits, we relied on both the Big Five and Type-D personality theories. The Big Five theory is widely used in psychology and is one of the most established approaches to describe individual personality traits ${ }^{26}$. On the other hand, the Type D personality theory was used to initially evaluate the association between patients with heart disease and mortality ${ }^{27}$; however, a recent study revealed an impact of Type $D$ personality on other chronic diseases ${ }^{28,29}$. As BOS and other occupational stress is often chronic, we thus assumed that Type D personality would also affect nurse BOS $^{30}$ and post-traumatic stress disorder symptoms (PTSD) ${ }^{31}$. The already-validated Japanese version of the ten-item personality measure (TIPI) is a measurement tool based on the Big Five theory consisting of 10 items and a 7-point Likert-scale to assess extraversion, agreeableness, conscientiousness, emotional stability and openness to experience ${ }^{32}$. We applied the original cutoff point for four subjective degrees ("Low", "Medium Low", "Medium High", "High") for each personality trait ${ }^{33}$ but treated them as dichotomous ( low and medium low as low, medium high and high as high) since skewed distributions and outliers might impart bias to the association between personality, ethical climate and BOS symptoms. Treating these personality traits as dichotomous increases the robustness of the interpretation. We also used the already-validated Japanese version of the Type-D personality Scale-14 (DS14) to test for Type D personalities ${ }^{34}$. The DS14 consists of 14 items on a 5-point Likert scale to assess Negative Affectivity (NA) and Social Inhibition (SI). Scores equal to or above 10 on both NA and SI indicate a Type $\mathrm{D}$ personality ${ }^{34}$.

\section{Measurement of ethical climate and professional QOL}

We measured HEC by the already-validated Japanese version of the Hospital Ethical Climate Survey (HECS) which consists of 26 items to assess the ethical climate of a workplace ${ }^{35,36}$. HECS is the one of the most widely used surveys, having been translated into many languages ${ }^{37-39}$, and it is recognized as having good psychometric properties for measuring ethical climates in health care organizations such as hospitals ${ }^{35}$. There are five domains, including peers, patients, managers, hospital and physicians, and a 5-point Likert scale that measures agreement with statements for each domain. We measured professional QOL by the already-validated Japanese version of the Professional Quality of Life Scale Version 5 (Pro-QOL V) ${ }^{40}$. The Pro-QOL V is the commonly used to measure BOS, STS, and CS in nurses, 
and consists of 30 items (10 items for each symptom) and a 5-point Likert scale that measures agreement with statements for each item ${ }^{40}$. Each subscale score of 22 or less were considered "low", levels of 23-41 were considered "moderate" and levels of 42 and above suggested "high" levels of the subject symptom.

\section{Statistics}

\section{Multivariate modeling}

For dichotomous variables we used Fisher's exact test for two groups, along with t-testing and ANOVA, followed by Tukey's test for multiple comparisons of continuous variables in univariate analyses. The outcome of interest was the relationship between personality traits and professional QOL. We evaluated each personality trait based on the Big Five theory and the association between BOS and the BOS-related symptoms STS and CS. We also evaluated the association between Type D personality and BOS, STS and CS. We used age ${ }^{9,41,42}$, sex ${ }^{8,9}$, marital status ${ }^{9,43}$, children ${ }^{8}$, exercise habit ${ }^{44}$ and experience years in ICU 41,45 as co-variates chosen a priori from the current literature. We applied general additive models (GAM) ${ }^{46,47}$ to examine the relationship between objective variables (BOS, STS and CS) and explanatory variables. GAM uses a non-linear link function to estimate relationships between objective variables and a smoothed function of explanatory variables ${ }^{48}$. A $p<0.05$ was considered statistically significant for all parameters.

\section{Interactions}

We hypothesized that HEC mediates the relationship between personality traits and each aspect of professional QOL (BOS, STS and CS). Therefore, we assumed the severity of the relationship between personality traits and professional QOL aspects is not equal by stratifying the severity of the HEC. Thus, we conducted GAM modeling, including only the main effects as above (model 1), but we also conducted interaction modeling using a thin-plate smoothing spline ${ }^{49}$ in the broad sense of smoothing splines for ANOVA (SSANOVA)(Model 2), Interaction modeling can explain the influence between the HEC level and personality traits on the outcome. All data were analyzed using the $\mathrm{R}$ software package.

\section{Sample size calculation}

Sample sizes were calculated based on the relationship between BOS and personality traits. Based on previous research, we assumed that effect size is slightly small $\mathrm{f}^{2}=0.02$ and we determined that 264 observations would be required for a significance level (a) of 0.05 and test power (1- $\beta$ ) of 0.80 .

\section{Ethics}

This study was carried out under laws equivalent to or derived from the principles of the Declaration of Helsinki and was approved by the University of Tsukuba Institutional Review Board (approval \# R01-142). 


\section{Results}

\section{Demographic data}

We enrolled 310 participants from September 2019 to February 2020 and

demographic data is shown in Table 1. The mean age of the participants was 33.1 years $( \pm 5.9)$ and about $70 \%$ were female. Approximately $55 \%$ of the participants were married and $65 \%$ were childless. About half $(54 \%)$ of the participants had hobbies and $29 \%$ had an exercise habit. Approximately $40 \%$ of the nurses had diplomas, with $35 \%$ of the nurses having a bachelor's degree and $1 \%$ had a doctorate. A majority of the nurses (36\%) earned between 47,000-57,000 USD annually and had an average nursing experience duration of $11.1( \pm 5.5)$ years and average ICU experience of $6.3( \pm 3.3)$ years.

\section{Distribution of personality traits}

As shown in Figure 1, the distribution of personality traits based on the Big Five theory did not significantly differ between Adult ICU, Adult/pediatric ICU and PICU categories for extraversion (Adult ICU: $3.8 \pm 1.2$ vs. Adult/pediatric ICU: $3.9 \pm 1.2$ vs. PICU: $3.6 \pm 0.9, p=0.35$ ), agreeableness (Adult ICU: $4.1 \pm 1.1$ vs. Adult/pediatric ICU: $4.3 \pm 1.1$ vs. PICU: $3.8 \pm 0.9, p=0.05$ ), conscientiousness (Adult ICU: $3.6 \pm 1.0$ vs. Adult/pediatric ICU: $3.8 \pm 1.0$ vs. PICU: $3.5 \pm 0.9, p=0.28$ ), neuroticism (Adult ICU: $3.6 \pm 1.1$ vs. Adult/pediatric ICU: $3.7 \pm 1.1$ vs. PICU: $3.9 \pm 0.9, p=0.21$ ), and openness (Adult ICU: $3.7 \pm 1.1$ vs. Adult/pediatric ICU: $3.9 \pm 1.2$ vs. PICU: $3.7 \pm 1.0, p=0.34$ ). With regard to the distribution of personality traits based on Type-D personality shown in Figure 2, the prevalence of Type-D personality did not significantly differ between Adult ICU, Adult/pediatric ICU and PICU categories (Adult ICU: $37 \%$ vs. Adult/pediatric ICU: $44 \%$ vs. pediatric ICU: $32 \%, p=0.67$ ). Differences in the NA (Adult ICU: $9.6 \pm 6.5$ vs. Adult/pediatric ICU: $9.2 \pm 5.6$ vs. pediatric ICU: $8.4 \pm 5.6, p=0.37$ ) and SI (Adult ICU: $9.6 \pm 5.6$ vs. Adult/pediatric ICU: $10.3 \pm 5.9$ vs. pediatric ICU: $9.1 \pm 4.8, p=0.37$ ) categories were also not significantly different.

\section{Severity of hospital ethical climate}

As shown in Figure 3 , The severity of total of ethical climate did not significantly differ between categories (Adult ICU: $67.5 \pm 12.1$ vs. Adult/pediatric ICU: $67.3 \pm 15.8$ vs. pediatric ICU: $66.1 \pm 10.1$, $p=0.69$ ) and no significant differences were seen for each component: peers (Adult ICU: $11 \pm 2.6 \mathrm{vs}$. Adult/pediatric ICU: $11.1 \pm 3.2$ vs. PICU: $10.5 \pm 2.5$, $p=0.38$ ), patients (Adult ICU: $11.5 \pm 2.3$ vs. Adult/pediatric ICU: $11.2 \pm 2.7$ vs. PICU: $11.4 \pm 2.1, p=0.66$ ), managers (Adult ICU: $14.7 \pm 4.8$ vs. Adult/pediatric ICU: $14.9 \pm 5.0$ vs. PICU: $13.8 \pm 3.4$, p=0.27), hospital (Adult ICU: $14.9 \pm 3.8$ vs. Adult/pediatric ICU: $14.5 \pm 3.9$ vs. PICU: $14.8 \pm 3.5, p=0.79$ ), and doctor (Adult ICU: $15.3 \pm 3.5$ vs. Adult/pediatric ICU: $15.4 \pm 4.2$ vs. PICU: $15.4 \pm 3.7, p=0.97$ ).

\section{Average severity of BOS, STS and CS}


As shown in Figure 4, the average BOS score in the PICU category was significantly lower compared with Adult ICU ( $p<0.05$ ) and Adult/pediatric ICU categories ( $p<0.05)$ (Adult ICU: $32 \pm 5.5$ vs. Adult/pediatric ICU: $33.5 \pm 5.6$ vs. PICU: $28.6 \pm 4.3$ ) while the average of severity of STS in the PICU category was also significantly lower compared with Adult ICU $(p<0.05)$ and Adult/pediatric ICU categories $(p<0.05)$ (Adult ICU: $28.5 \pm 4.6$ vs. Adult/pediatric ICU: $28.8 \pm 6.1$ vs. PICU: $26.7 \pm 3.9)$. Moreover, the average severity of $\mathrm{CS}$ in the PICU category was significantly higher compared with Adult ICU $(p<0.05)$, and Adult/pediatric ICU categories $(p<0.05)$ (Adult ICU: $29.3 \pm 5.5$ vs. Adult/pediatric ICU: $30.5 \pm 6.8$ vs. PICU: $32.7 \pm 5.4$ ).

\section{Factors associated with BOS, STS and CS by univariate analysis}

Exercise habits and improved total HECS scores $(p=0.01)$, plus each component of HECS $(p<0.01)$ were significantly associated with decreased BOS $(p<0.01)$, neuroticism $(p=0.01)$, and Type-D personality $(p<0.01)$ while the components of type $D$ personality $(N A[p<0.01]$ and $S I[p=0.01])$ were associated with increased BOS. Age $(p=0.02)$, hobby $(p=0.04)$, years of nursing experience $(p=0.04)$, years of ICU experience $(p=0.03)$, extraversion $(p<0.01)$, agreeableness $(p<0.01)$ and improved total HECS score $(p<0.01)$ plus each component of HECS (peers: $p<0.01$, patients: $p=0.01$, managers: $p<0.01$, hospital: $p<0.01$, doctor: $p<0.01)$ were associated with decreased STS while female $(p=0.02)$, neuroticism $(p=0.02)$, Type-D personality $(p<0.01)$ plus each component of type $D$ personality, NA $(p=0.01)$ and $S I(p=0.02)$ were associated with increased STS. On the other hand, age $(p<0.01)$, number of children $(p=0.04)$, exercise habit $(p<0.01)$, years of nursing experience $(p=0.01)$, years of ICU experience $(p<0.01)$, extraversion $(p<0.01)$, agreeableness $(p<0.01)$, openness $(p=0.03)$ and improved total HECS score $(p<0.01)$ plus each component of HECS were associated with increased CS ( $p<0.01$ of all) but only neuroticism was associated with decreased CS $(\mathrm{p}=0.03)$. Complete results of this univariate modeling are available online (Supplementary File 1).

\section{Associations between personality traits and HEC for BOS, STS and CS by multivariate analysis}

Table 2 shows the results of the multivariate analysis. Neuroticism $(p=0.03)$, Type-D personality $(p<0.01)$ plus each component of type D personality, NA $(p<0.01)$ and $S I(p=0.01)$, and total HECS score $(p<0.01)$ plus each component of HECS (except Peers) were associated with increased BOS (Patients: $p<0.01$, Managers: $p<0.01$, Hospital: $p<0.01$, Doctor: $p<0.01)$. All the risk factors for increased BOS were also risk factors for increased STS and agreeableness $(p<0.01)$, and peer component of HECS $(p<0.01)$ were an additional associated factor for STS. For CS, extraversion $(p=0.01)$, agreeableness $(p<0.01)$, openness $(p=0.01)$, and total HECS score $(p<0.01)$ plus each component of HECS were associated with increased CS ( $p<0.01$ for all). Of all the multivariate modeling, only exercise habit was independently associated with increased BOS and STS but decreased CS. Detailed results of multivariate modeling, including covariates for each personality trait and HEC (including covariates), are available online. (Supplementary File 2)

\section{Interaction between HEC and personality traits based on Big Five theory for BOS, STS and CS}


We show the interaction between ethical climate and personality traits based on the Big Five theory for BOS, STS and CS in Figure 5. We observed an interaction between ethical climate, conscientiousness $(p<0.01)$ and neuroticism $(p=0.01)$ for BOS, an interaction for STS between ethical climate and conscientiousness $(p<0.01)$, and an interaction for CS between ethical climate and neuroticism $(p=0.01)$. This result indicated that worse ethical climates increase the magnitude of BOS, STS and CS for nurses possessing specific personality traits. We also observed that high conscientiousness nurses did not answer more than 88 out of 120 questions for HECS compared with 111 out of 120 questions in the low conscientiousness group. This difference was also seen in agreeableness as high agreeableness nurses did not answer less than 50 out of 120 questions for HECS compared with 22 out of 120 questions in the low agreeableness group. Detailed results of Interaction between HEC and personality traits based on Big Five theory for BOS, STS and CS are available online. (Supplementary File 3)

\section{Interaction between ethical climate and Type D personality for BOS, STS and CS}

We also show the interaction between HEC and Type D personality for BOS, STS and CS in Figure 6. An interaction between ethical climate and Type D personality for BOS $(p<0.01)$ and STS $(p<0.01)$ but not CS $(p=0.29)$ was observed, indicating that a substandard ethical climate increases the magnitude of BOS and STS (but not CS) for Type D personality nurses.

\section{Discussion}

The present study is the first to reveal the relationship between personality traits, hospital ethical climate and professional QOL. Here, we showed that HEC is independently associated with professional QOL (BOS, STS,CS) (Hypothesis 1) and also that specific personality traits are independently associated with BOS, STS and CS (Type-D personality for BOS and STS: Extraversion for CS: Agreeableness for STS and CS: Neuroticism for BOS and STS: Openness for CS: ) (Hypothesis 2). Moreover, the interaction between HEC and specific personality traits for professional QOL (Type-D personality for BOS and STS:

Conscientiousness for BOS and STS: Neuroticism for BOS and CS) indicate that HEC strongly affects the magnitude of professional QOL in nurses with specific personality traits. (Hypothesis 3 )

The average BOS, STS and CS scores in our cohort were $31.5( \pm 5.6), 28.1( \pm 4.9)$ and $30.4( \pm 6.0)$, respectively, and these average BOS and STS scores are similar to a previous report evaluating all nurses in Japan ${ }^{40}$. The STS average score we obtained was also similar to a previous study from China regarding various departments, including the $\mathrm{ICU}^{25}$, which indicates that our cohort was an appropriate cross section of nurses and that our results are generally applicable to Asian nursing populations.

We also revealed differences with regard to professional QOL between adult, adult/pediatric and PICU nurses. The PICU nurses had significantly lower BOS and STS, coupled with significantly high CS, even though the demographic data and personality traits were not significantly different. As a previous study reported that those in pediatric care are subject to high levels of stress and burnout risk ${ }^{7}$ and a metaanalysis also revealed a BOS high prevalence in pediatric nurses, this conflicts with our results. ${ }^{50}$ Another 
systematic review indicated that adult intensive care nurses are a high risk population ${ }^{51}$ but, as the PICU is still a new therapeutic area ${ }^{52}$, there are fewer professional QOL comparisons between PICU and other nursing professions. One study that included both adult and pediatric intensive care nurses found no differences ${ }^{53}$ but adult intensive care unit nurses may more frequently face the deaths of their patients, impacting professional QOL ${ }^{54}$. Taking into account that observing death is a strong risk factor for BOS, ${ }^{12}$ our finding that pediatric nurses have lower BOS and STS but higher CS is reasonable.

Regarding the risk factors for BOS and CS, exercise habits are significantly associated with BOS and CS. As a previous review already reported reductions in BOS within general occupational health, ${ }^{44}$ our study is in line with this review and also showed the robustness of the strong association between exercise and BOS. Interestingly, exercise was significantly associated not only with BOS but CS. As Stamm et al conceptualized BOS, CS and STS as the facets of professional QOL, it is sensible that exercise's effect on reduction of BOS could increase CS ${ }^{23}$

We also revealed an interaction between hospital ethical climate and specific personality traits for BOS, CS and STS. According to the Big Five theory, conscientiousness positively interacts with hospital ethical climate and BOS/STS which drives the idea that personality is a key factor in assessing professional QOL. Likewise, neuroticism has a similar but negative interaction with hospital ethical climate and BOS and CS. Moreover, Type D personality also interacts with ethical climate and BOS and STS which leads to the conclusion that that the effect of hospital ethical climate on BOS and STS is mediated by aspects of the Type $D$ personality.

Several studies have revealed the associations between personality and BOS and ethical climate and BOS. However, humans are dual aspect creatures living in both a social community and as individuals. Thus, the ethical climate must be thought of as a representative barometer of the atmosphere of the working place as a social community while personality traits are representative of the individual thinking. From our result, hospital ethical climate and personality traits with regard to professional QOL and its facets, including BOS, STS and CS, are thus significantly associated. Therefore, for clinical implications, we advocate that administrators take personality traits into account and also create a good hospital ethical climate to maintain professional QOL in high-stress nursing departments. Additionally, nurses possessing conscientiousness, neuroticism and Type-D personality traits are sensitive to hospital ethical climates, are at risk for BOS and should be supported to increase their professional QOL.

This observational study demonstrated links between personality traits, ethical climate and professional QOL. Further studies should be conducted on interventional approaches that consider personality traits in counseling to increase professional QOL. Because a substandard ethical climate greatly decreases professional QOL for specific personalities, this association must be considered for interpretation of any intervention-based results.

There is still a worldwide shortage of nurses, estimated to reach to 7.6 million in the year $2030^{55}$. This number will invariably be inflated because of the COVID-19 pandemic and medical staff are now facing 
difficulties that place tremendous pressure on professional QOL. Taking into account the close relationship between personality, compassion, ethical climate and professional QOL, new studies focusing on strategies to retain nurses will be needed to ameliorate the nursing shortage in this pandemic age.

\section{Limitations}

There are some limitations to this study. First, we conducted a cross-sectional study and therefore cannot mention any causal relationships. Second, we used an online survey system for gathering participants which might have led to self-selection and/or non-respondent bias. Self-selection and non-respondent biases are difficult to control for in questionnaire studies since we could not survey the non-responders for ethical reasons and these nurses may have refused participation because of a higher level of BOS. However, in spite of the limitations inherent in a cross-sectional study, this report still demonstrates a significant interaction between hospital ethical climate and specific personality traits with regard to professional QOL that could serve to bring insight into counteracting BOS and STS in PICU nurses.

\section{Conclusion}

We conducted a cross-sectional study showing hospital ethical climate and specific personality traits as independent factors for professional QOL. Additionally, the magnitude of professional QOL is linked to the interaction between the hospital ethical climate and these specific personality traits. Therefore, it is important for hospital management to consider the impact of individual personalities with regard to the ethical climate when planning interventions.

\section{Declarations}

\section{Acknowledgments}

None

\section{Conflicts of interest}

None

\section{Funding}

None

\section{Authors' contributions}

YM, BM designed the study and carried out sample collection, data analysis, and wrote the manuscript. $\mathrm{HS}, \mathrm{HH}, \mathrm{YE}, \mathrm{NS}$, SK and YI participated in designing study. All authors read and approved the final manuscript. 


\section{Disclosure}

None

\section{Competing interests}

The authors declare that they have no competing interests.

\section{References}

1. Freudenberger, H. J. Staff Burn-Out. J Soc Issues. 30 (1), 159-165 https://doi.org/10.1111/j.15404560.1974.tb00706.x (1974).

2. Maslach, C., Jackson, S. E. \& Leiter, M. P. In: Evaluating Stress: A Book of Resources191218(Scarecrow Education, Lanham, MD, US, 1997). Maslach Burnout Inventory: Third edition

3. Maslach, C. \& Jackson, S. E. The measurement of experienced burnout. J Organ Behav. 2 (2), 99113 https://doi.org/10.1002/job.4030020205 (1981).

4. Organization, W. H. The 11th Revision of the International Classification of Diseases (ICD-11). https://icd.who.int/en/. Accessed August 15, 2019.

5. Buckley, P. Work related stress, depression or anxiety in Great Britain. http://www.hse.gov.uk/statistics/causdis/stress/index.htm. Published 2018. Accessed August 15, 2019.

6. Moss, M., Good, V. S., Gozal, D., Kleinpell, R. \& Sessler, C. N. A Critical Care Societies Collaborative Statement: Burnout Syndrome in Critical Care Health-care Professionals. A Call for Action. Am J Respir Crit Care Med. 194 (1), 106-113 https://doi.org/10.1164/rccm.201604-0708ST (2016).

7. Robins, P. M., Meltzer, L. \& Zelikovsky, N. The Experience of Secondary Traumatic Stress Upon Care Providers Working Within a Children's Hospital. J Pediatr Nurs. 24 (4), 270-279 https://doi.org/10.1016/j.pedn.2008.03.007 (2009).

8. Teixeira, C., Ribeiro, O., Fonseca, A. M. \& Carvalho, A. S. Burnout in intensive care units - a consideration of the possible prevalence and frequency of new risk factors: A descriptive correlational multicentre study. BMC Anesthesiol. 13, https://doi.org/10.1186/1471-2253-13-38 (2013).

9. Merlani, P. et al. Burnout in ICU caregivers: A multicenter study of factors associated to centers. Am J Respir Crit Care Med. 184 (10), 1140-1146 https://doi.org/10.1164/rccm.201101-00680C (2011).

10. Azoulay, E. \& Herridge, M. Understanding ICU staff burnout: The show must go on. Am J Respir Crit Care Med. 184 (10), 1099-1100 https://doi.org/10.1164/rccm.201109-1638ED (2011).

11. Abdo, S. A. M., El-Sallamy, R. M., El-Sherbiny, A. A. M. \& Kabbash, I. A. the emergency hospital of Tanta university, Egypt. East Mediterr Heal J. 21 (12), 906-915 (2015). Burnout among physicians and nursing staff working ifile://C:/Users/user/Desktop/1-s2.0-S2213058614000254-main.pdfn 
12. Aiken, L. H. Hospital Nurse Staffing and Patient Mortality, Nurse Burnout, and Job Dissatisfaction. JAMA. 288 (16), 1987 https://doi.org/10.1001/jama.288.16.1987 (2002).

13. Teng, C. I., Shyu, Y. I. L., Chiou, W. K., Fan, H. C. \& Lam, S. M. Interactive effects of nurse-experienced time pressure and burnout on patient safety: A cross-sectional survey. Int J Nurs Stud. 47 (11), 14421450 https://doi.org/10.1016/j.jinurstu.2010.04.005 (2010).

14. Liu, X. et al. Hospital nursing organizational factors, nursing care left undone, and nurse burnout as predictors of patient safety: A structural equation modeling analysis. Int J Nurs Stud. 86, 82-89 https://doi.org/10.1016/j.ijnurstu.2018.05.005 (2018).

15. Fletcher, C. E. Hospital RNs' job satisfactions and dissatisfactions. J Nurs Adm. 31 (6), 324-331 https://doi.org/10.1097/00005110-200106000-00011 (2001).

16. Taylor, S., White, B. \& Muncer, S. Nurses' cognitive structural models of work-based stress. J Adv Nurs. 29 (4), 974-983 https://doi.org/10.1046/j.1365-2648.1999.00980.x (1999).

17. Garrosa, E., Moreno-Jiménez, B., Liang, Y. \& González, J. L. The relationship between sociodemographic variables, job stressors, burnout, and hardy personality in nurses: An exploratory study. Int J Nurs Stud. 45 (3), 418-427 https://doi.org/10.1016/j.ijnurstu.2006.09.003 (2008).

18. Garrosa, E., Moreno-Jiménez, B., Rodríguez-Muñoz, A. \& Rodríguez-Carvajal, R. Role stress and personal resources in nursing: A cross-sectional study of burnout and engagement. Int J Nurs Stud. 48 (4), 479-489 https://doi.org/10.1016/j.jinurstu.2010.08.004 (2011).

19. Losa Iglesias, M. E., Vallejo, R. B. \& de Fuentes, B. PS. The relationship between experiential avoidance and burnout syndrome in critical care nurses: A cross-sectional questionnaire survey. Int $J$ Nurs Stud. 47 (1), 30-37 https://doi.org/10.1016/j.ijnurstu.2009.06.014 (2010).

20. Garrosa, E., Rainho, C., Moreno-Jiménez, B. \& Monteiro, M. J. The relationship between job stressors, hardy personality, coping resources and burnout in a sample of nurses: A correlational study at two time points. Int J Nurs Stud. 47 (2), 205-215 https://doi.org/10.1016/j.ijnurstu.2009.05.014 (2010).

21. Ang, S. Y. et al. Demographics and Personality Factors Associated with Burnout among Nurses in a Singapore Tertiary Hospital. Biomed Res Int. 2016, https://doi.org/10.1155/2016/6960184 (2016).

22. Geuens, N., Braspenning, M., Van Bogaert, P. \& Franck, E. Individual vulnerability to burnout in nurses: The role of Type D personality within different nursing specialty areas. Burn Res. 2 (2-3), 80-86 https://doi.org/10.1016/j.burn.2015.05.003 (2015).

23. Stamm, B. H. The Concise ProQOL Manual (2nd Ed.) (ProQOL.org, Pocatello, ID, 2010).

24. Jenkins, B. \& Warren, N. A. Concept analysis: Compassion fatigue and effects upon critical care nurses. Crit Care Nurs Q. 35 (4), 388-395 https://doi.org/10.1097/CNQ.0b013e318268fe09 (2012).

25. Wang, J. et al. Factors associated with compassion satisfaction, burnout, and secondary traumatic stress among Chinese nurses in tertiary hospitals: A cross-sectional study. Int J Nurs Stud. 102, 103472 https://doi.org/10.1016/j.ijnurstu.2019.103472 (2020).

26. Power, R. A. \& Pluess, M. Heritability estimates of the Big Five personality traits based on common genetic variants. Trans/ Psychiatry. 5 (7), e604 https://doi.org/10.1038/tp.2015.96 (2015). 
27. Denollet, J. et al. Personality as independent predictor of long-term mortality in patients with coronary heart disease. Lancet (London, England). 347 (8999), 417-421 https://doi.org/10.1016/S0140-6736(96)90007-0 (1996).

28. Garip, Y., Güler, T., Bozkurt Tuncer, Ã. \& Önen, S. Type d personality is associated with disease severity and poor quality of life in turkish patients with fibromyalgia syndrome: A cross-sectional study. Arch Rheumatol. 35 (1), 13-19 https://doi.org/10.5606/ArchRheumatol.2020.7334 (2020).

29. Lin, Y. H., Chen, D. A., Lin, C. \& Huang, H. Type d personality is associated with glycemic control and socio-psychological factors on patients with type 2 diabetes mellitus: A cross-sectional study. Psychol Res Behav Manag. 13, 373-381 https://doi.org/10.2147/PRBM.S245226 (2020).

30. Kim, Y. H. et al. Influence of type D personality on job stress and job satisfaction in clinical nurses: The mediating effects of compassion fatigue, burnout, and compassion satisfaction. J Adv Nurs. 73 (4), 905-916 https://doi.org/10.1111/jan.13177 (2017).

31. Cho, G. J. \& Kang, J. Type D personality and post-traumatic stress disorder symptoms among intensive care unit nurses: The mediating effect of resilience. PLoS One. 12 (4), 1-10 https://doi.org/10.1371/journal.pone.0175067 (2017).

32. Oshio, A., Abe, S. \& Cutrone, P. Development, Reliability, and Validity of the Japanese Version of Ten Item Personality Inventory (TIPI-J). Japanese J Personal. 21 (1), 40-52 https://doi.org/10.2132/personality.21.40 (2012).

33. Gosling, S. D., Rentfrow, P. J. \& Swann, W. B. A very brief measure of the Big-Five personality domains. J Res Pers. 37 (6), 504-528 https://doi.org/10.1016/S0092-6566(03)00046-1 (2003).

34. Ishihara, S., Uchibori, T., Imai, A. \& Makita, S. Development of the Japanese version of Type D scale for patients with coronary heart disease. Japanese J Heal Psychol. 27, 177-184 (2015).

35. Olson, L. L. Hospital Nurses' Perceptions of the Ethical Climate of Their Work Setting. Image $J$ Nurs Scholarsh. 30 (4), 345-349 https://doi.org/10.1111/j.1547-5069.1998.tb01331.x (1998).

36. Mikane, S. et al. The validity and reliability of the Japanese version of the Hospital Ethical Climate Survey. Conf Pap 32nd Annu Meet Japan Soc Nurs Res. 2019:51.

37. Bahcecik, N. \& Oztürk, H. The Hospital Ethical Climate Survey in Turkey. JONAS Healthc Law Ethics Regul. 5 (4), 94-99 https://doi.org/10.1097/00128488-200312000-00008 (2003).

38. Rivaz, M., Rakhshan, M., Vizeshfar, F. \& Setoodegan, E. Validation of the Iranian Version of the Hospital Ethical Climate Survey. J Nurs Meas. March. https://doi.org/10.1891/JNM-D-18-00086 (2020).

39. Charalambous, A., Cloconi, C., Papastavrou, E. \& Theodoula, A. Psychometric Properties of the Hospital Ethical Climate Survey: A Cross-Sectional Study in Greek and Cypriot Cancer Care Settings. J Nurs Meas. 26 (2), 237-248 https://doi.org/10.1891/1061-3749.26.2.237 (2018).

40. Fukumori, T., Goto, T. \& Sato, H. Development, reliability, and validity of a Japanese version of the Professional Quality of Life Scale for Nurses. Shinrigaku Kenkyu. 89 (2), 150-159 https://doi.org/10.4992/jjpsy.89.17202 (2018). 
41. Aytekin, A., Yılmaz, F. \& Kuğuoğlu, S. Burnout levels in neonatal intensive care nurses and its effects on their quality of life. Aust J Adv Nurs. 31 (2), 39-48 (2014).

42. Mealer, M. et al. psychological profile in ICU nurses: Results of a national survey. Int J Nurs Study. 49 (3), 292-299 https://doi.org/10.1016/j.ijnurstu.2011.09.015.The (2013).

43. Ayala, E. \& Carnero, A. M. Determinants of Burnout in Acute and Critical Care Military Nursing Personnel: A Cross-Sectional Study from Peru. PLoS One. 8 (1), https://doi.org/10.1371/journal.pone.0054408 (2013).

44. Naczenski, L. M., de Vries, J. D., van Hooff, M. L. M. \& Kompier, M. A. J. Systematic review of the association between physical activity and burnout. J Occup Health. 59 (6), 477-494 https://doi.org/10.1539/joh.17-0050-RA (2017).

45. Galván, M. E. et al. Professional burnout in pediatric intensive care units in Argentina. Arch Argent Pediatr. 110 (6), 466-473 https://doi.org/10.5546/aap.2012.466 (2012).

46. Young, R. L., Weinberg, J., Vieira, V., Ozonoff, A. \& Webster, T. F. Generalized Additive Models and Inflated Type I Error Rates of Smoother Significance Tests. Comput Stat Data Anal. 55 (1), 366-374 https://doi.org/10.1016/j.csda.2010.05.004 (2011).

47. Hastie, T. \& Tibshirani, R. Generalized Additive Models: Some Applications. J Am Stat Assoc. 82 (398), 371-386 https://doi.org/10.1080/01621459.1987.10478440 (1987).

48. Desquilbet, L. \& Mariotti, F. Dose-response analyses using restricted cubic spline functions in public health research. Stat Med. 29 (9), 1037-1057 https://doi.org/10.1002/sim.3841 (2010).

49. Green, P. J. BWS. Nonparametric Regression and Generalized Linear Models: A Roughness Penalty Approach. Chapman and Hall/CRC; 1993.

50. Pradas-Hernández, L., Ariza, T., Gómez-Urquiza, J. L., Albendín-García, L. \& De la Fuente, E. I. Cañadas-De la Fuente GA. Prevalence of burnout in paediatric nurses: A systematic review and metaanalysis. PLoS One. 13 (4), 25-37 https://doi.org/10.1371/journal.pone.0195039 (2018).

51. Chuang, C. H., Tseng, P. C., Lin, C. Y., Lin, K. H. \& Chen, Y. Y. Burnout in the intensive care unit professionals: A systematic review. Med (United States). 95 (50), e5629 https://doi.org/10.1097/MD.0000000000005629 (2016).

52. Epstein, D. \& Brill, J. E. A History of Pediatric Critical Care Medicine. Pediatr Res. 58 (5), $987-996$ https://doi.org/10.1203/01.PDR.0000182822.16263.3D (2005).

53. Colville, G. A. et al. Coping with Staff Burnout and Work-Related Posttraumatic Stress in Intensive Care. Pediatr Crit Care Med. 18 (7), e267-e273 https://doi.org/10.1097/PCC.0000000000001179 (2017).

54. Namachivayam, P. et al. Three decades of pediatric intensive care: Who was admitted, what happened in intensive care, and what happened afterward*. Pediatr Crit Care Med. 11 (5), $549-555$ https://doi.org/10.1097/PCC.0b013e3181ce7427 (2010).

55. Organization, W. H. Global strategy on human resources for health: Workforce 2030.WHO. 2016:64. doi:10.1017/CB09781107415324.004 


\section{Tables}

Due to technical limitations, table 1,2 is only available as a download in the Supplemental Files section.

\section{Figures}

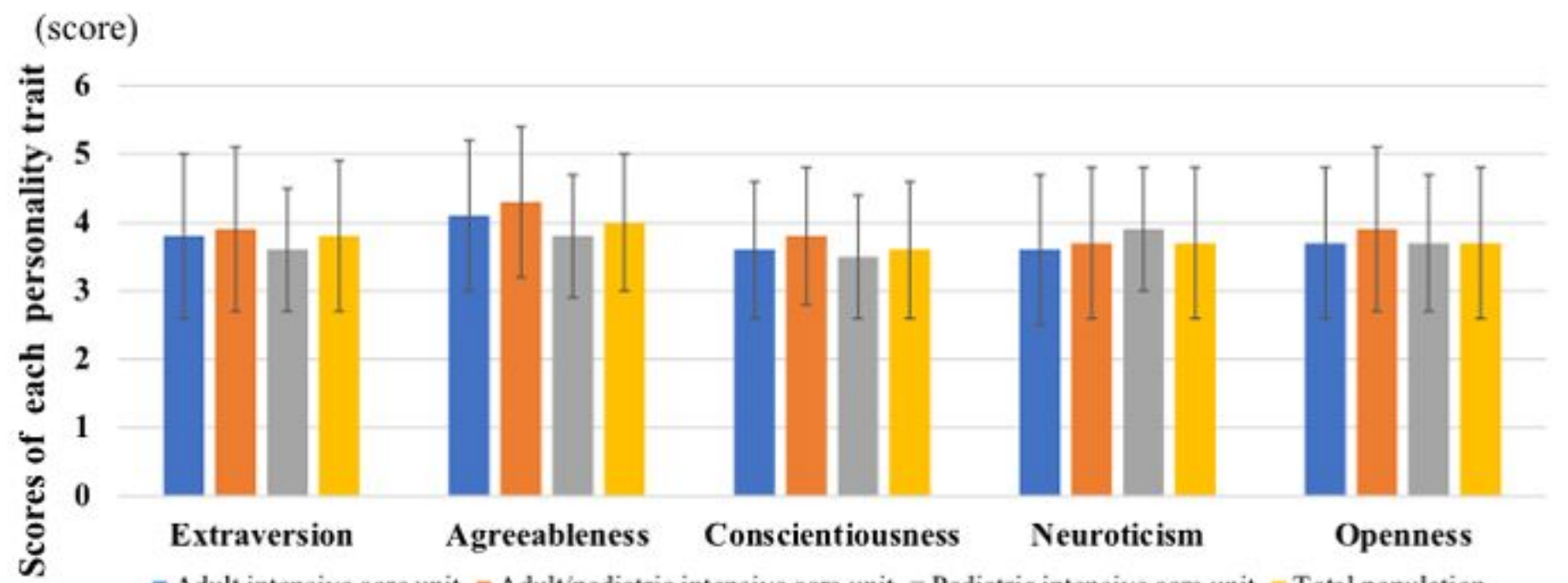

= Adult intensive care unit $=$ Adult pediatric intensive care unit $=$ Pediatric intensive care unit $=$ Total population

\begin{tabular}{|l|c|c|c|c|}
\hline \multicolumn{1}{|c|}{ variable } & $\begin{array}{c}\text { Adult } \\
\text { intensive care unit } \\
\mathrm{N}=160\end{array}$ & $\begin{array}{c}\text { Adult/pediatric } \\
\text { intensive care unit } \\
\mathrm{N}=74\end{array}$ & $\begin{array}{c}\text { Pediatric } \\
\text { intensive care unit } \\
\mathrm{N}=76\end{array}$ & $\begin{array}{c}\text { Total population } \\
\mathrm{N}=310\end{array}$ \\
\hline $\begin{array}{l}\text { Big five theory-Extraversion, } \\
\text { Average } \pm \mathrm{SD}\end{array}$ & $3.8 \pm 1.2$ & $3.9 \pm 1.2$ & $3.6 \pm 0.9$ & $3.8 \pm 1.1$ \\
\hline $\begin{array}{l}\text { Big five theory-Agreeableness, } \\
\text { Average } \pm \text { SD }\end{array}$ & $4.1 \pm 1.1$ & $4.3 \pm 1.1$ & $3.8 \pm 0.9$ & $4.0 \pm 1.0$ \\
\hline $\begin{array}{l}\text { Big five theory-Conscientiousness, } \\
\text { Average } \pm \text { SD }\end{array}$ & $3.6 \pm 1.0$ & $3.8 \pm 1.0$ & $3.5 \pm 0.9$ & $3.6 \pm 1.0$ \\
\hline $\begin{array}{l}\text { Big five theory -Neuroticism, } \\
\text { Average } \pm \text { SD }\end{array}$ & $3.6 \pm 1.1$ & $3.7 \pm 1.1$ & $3.9 \pm 0.9$ & $3.7 \pm 1.1$ \\
\hline $\begin{array}{l}\text { Big five theory -Openness, } \\
\text { Average } \pm \text { SD }\end{array}$ & $3.7 \pm 1.1$ & $3.9 \pm 1.2$ & $3.7 \pm 1.0$ & $3.7 \pm 1.1$ \\
\hline
\end{tabular}

*:significantly different from Adult intensive care unit, $\uparrow:$ :significantly different from Adult/pediatric intensive care unit \$:significantly different from pediatric intensive care unit,

\section{Figure 1}

Distribution of personality traits based on Big Five theory This figure shows the distribution of personality traits for based on Big Five theory for each intensive care unit. 
(score)

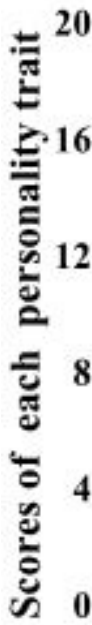

0

\section{Negative Affectivity}

- Adult intensive care unit

adult/pediatric intensive care unit

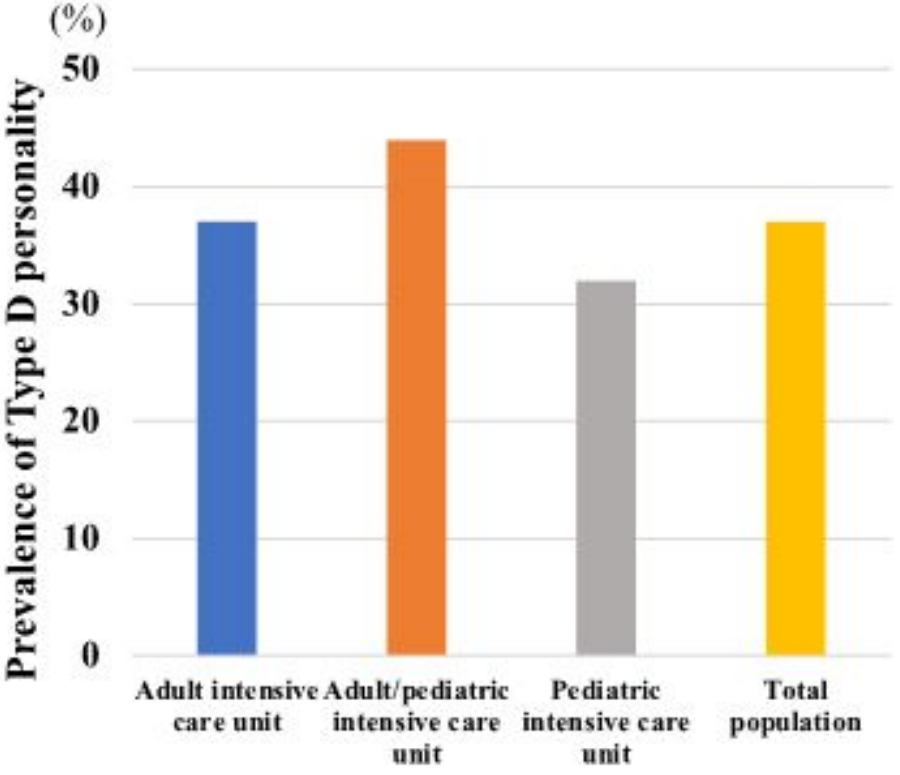

$=$ Total population

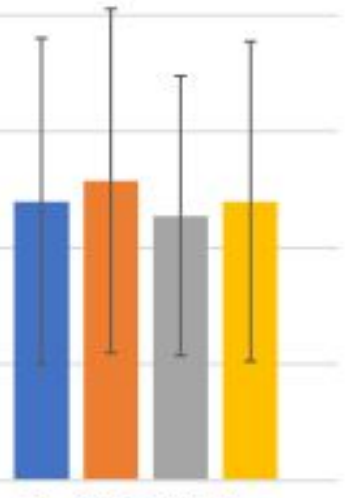

Social Inhibition

= Pediatric intensive care unit

\begin{tabular}{|l|c|c|c|c|}
\hline \multicolumn{1}{|c|}{ variable } & $\begin{array}{c}\text { Adult } \\
\text { intensive care unit } \\
\mathrm{N}=160\end{array}$ & $\begin{array}{c}\text { Adult/pediatric } \\
\text { intensive care unit } \\
\mathrm{N}=74\end{array}$ & $\begin{array}{c}\text { Pediatric } \\
\text { intensive care unit } \\
\mathrm{N}=76\end{array}$ & $\begin{array}{c}\text { Total population } \\
\mathrm{N}=310\end{array}$ \\
\hline Type D personality, $\mathrm{n}(\%)$ & $60(37)$ & $33(44)$ & $25(32)$ & $118(37)$ \\
\hline $\begin{array}{l}\text { Type D personality } \\
- \text { Negative Affectivity (NA), } \\
\text { Average } \pm \text { SD }\end{array}$ & $9.6 \pm 6.5$ & $9.2 \pm 5.6$ & $8.4 \pm 5.6$ & $9.2 \pm 6.1$ \\
\hline $\begin{array}{l}\text { Type D personality } \\
- \text { Social Inhibition (SI), } \\
\text { Average } \pm \text { SD }\end{array}$ & $9.6 \pm 5.6$ & $10.3 \pm 5.9$ & $9.1 \pm 4.8$ & $9.6 \pm 5.5$ \\
\hline
\end{tabular}

*:significantly different from Adult intensive care unit, $\uparrow:$ :significantly different from Adult/pediatric intensive care unit \$:significantly different from pediatric intensive care unit,

\section{Figure 2}

Distribution of personality traits based on Type $D$ personality This figure shows the distribution of personality traits for based on Type $D$ personality for each intensive care unit. 


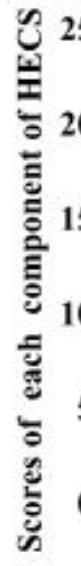

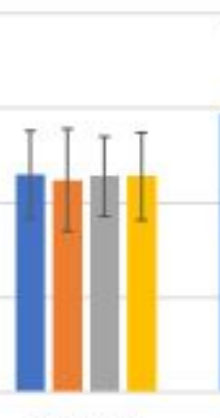

Patients

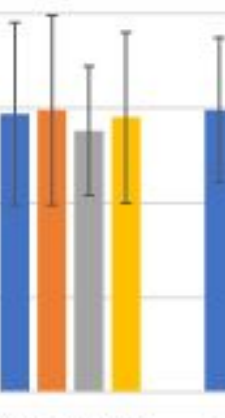

Managers

\section{Hospital}

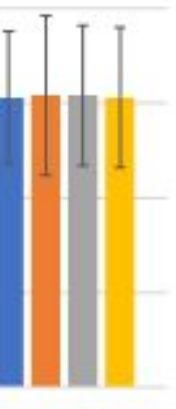

Doctor

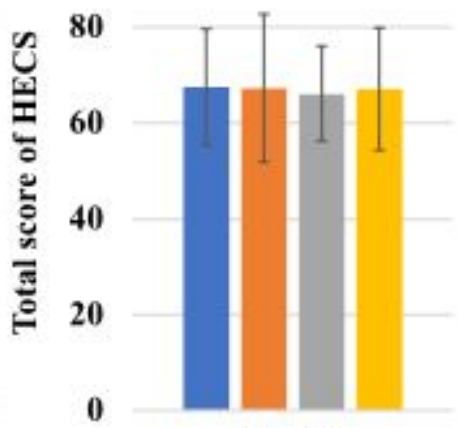

Total

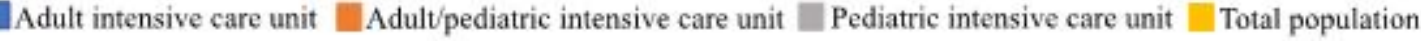

\begin{tabular}{|l|c|c|c|c|}
\hline \multicolumn{1}{|c|}{ variable } & $\begin{array}{c}\text { Adult } \\
\text { intensive care unit } \\
\mathrm{N}=160\end{array}$ & $\begin{array}{c}\text { Adult/pediatric } \\
\text { intensive care unit } \\
\mathrm{N}=74\end{array}$ & $\begin{array}{c}\text { Pediatric } \\
\text { intensive care unit } \\
\mathrm{N}=76\end{array}$ & $\begin{array}{c}\text { Total population } \\
\mathrm{N}=310\end{array}$ \\
\hline $\begin{array}{l}\text { HECS }- \text { Peer, } \\
\text { Average } \pm \text { SD }\end{array}$ & $11 \pm 2.6$ & $11.1 \pm 3.2$ & $10.5 \pm 2.5$ & $10.9 \pm 2.7$ \\
\hline $\begin{array}{l}\text { HECS }- \text { Patients, } \\
\text { Average } \pm \text { SD }\end{array}$ & $11.5 \pm 2.3$ & $11.2 \pm 2.7$ & $11.4 \pm 2.1$ & $11.4 \pm 2.3$ \\
\hline $\begin{array}{l}\text { HECS -Managers, } \\
\text { Average } \pm \text { SD }\end{array}$ & $14.9 \pm 3.8$ & $14.5 \pm 3.9$ & $14.8 \pm 3.5$ & $14.8 \pm 3.7$ \\
\hline $\begin{array}{l}\text { HECS -Hospital, } \\
\text { Average } \pm \text { SD }\end{array}$ & $15.3 \pm 3.5$ & $15.4 \pm 4.2$ & $15.4 \pm 3.7$ & $15.3 \pm 3.7$ \\
\hline $\begin{array}{l}\text { HECS -Doctor, } \\
\text { Average } \pm \text { SD }\end{array}$ & $67.5 \pm 12.1$ & $67.3 \pm 15.8$ & $66.1 \pm 10.1$ & $67.1 \pm 12.7$ \\
\hline $\begin{array}{l}\text { HECS -Total, } \\
\text { Average } \pm \text { SD }\end{array}$ & & $14.9 \pm 5.0$ & $13.8 \pm 3.4$ & $14.5 \pm 4.5$ \\
\hline
\end{tabular}

*:significantly different from Adult intensive care unit, $\uparrow:$ : significantly different from Adult/pediatric intensive care $u$ \$:significantly different from pediatric intensive care unit,

\section{Figure 3}

Severity of hospital ethical climate This figure shows the distribution of Severity of hospital ethical climate for each intensive care unit. 

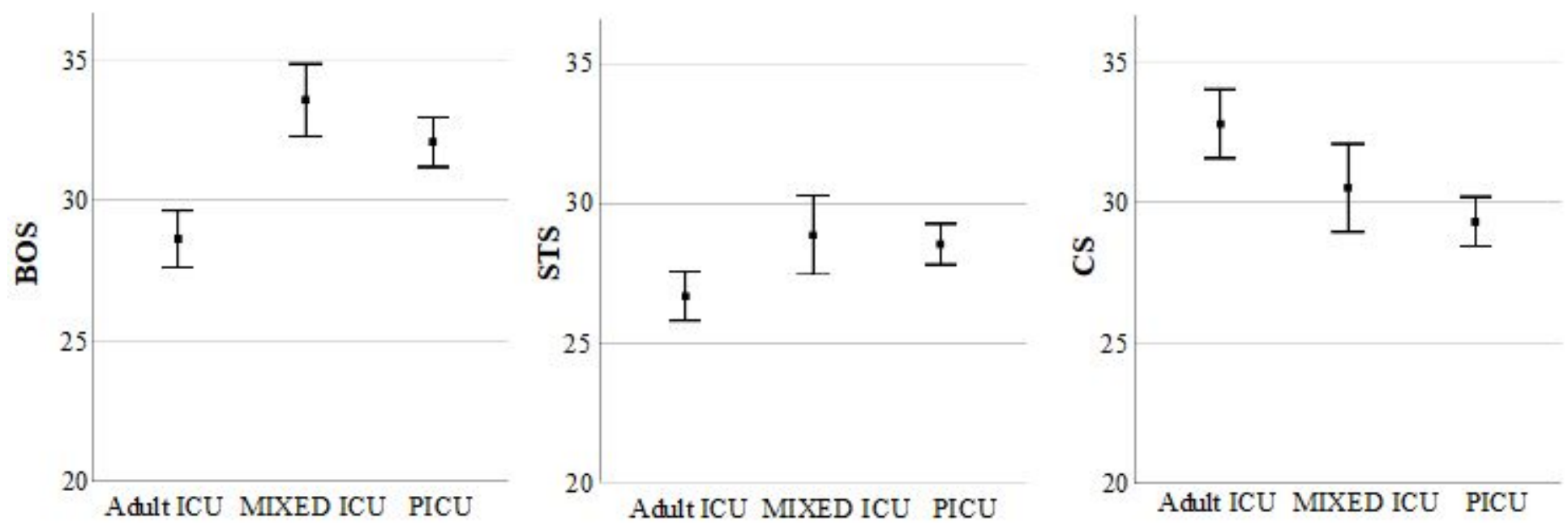

\begin{tabular}{|c|c|c|c|c|}
\hline & $\begin{array}{c}\text { Adult } \\
\text { intensive care unit } \\
N=160\end{array}$ & $\begin{array}{c}\text { Adult/pediatric } \\
\text { intensive care unit } \\
\mathrm{N}=74\end{array}$ & $\begin{array}{c}\text { Pediatric } \\
\text { intensive care unit } \\
\mathrm{N}=76\end{array}$ & $\begin{array}{c}\text { Total population } \\
\qquad \mathrm{N}=310\end{array}$ \\
\hline $\begin{array}{l}\text { ProQOL V-burnout syndrome } \\
\text { Average } \pm \mathrm{SD} \\
\text { High level, } \mathrm{n}(\%) \\
\text { Moderate level, } \mathrm{n}(\%) \\
\text { Low level, } \mathrm{n}(\%) \\
\end{array}$ & $\begin{array}{c}32 \pm 5.5^{\dagger}, \ddagger \\
9(6) \\
148(92) \\
3(2) \\
\end{array}$ & $\begin{array}{l}33.5 \pm 5.6^{*}: \neq \\
2(3) \\
66(89) \\
6(8)\end{array}$ & $\begin{array}{c}28.6 \pm 4.3^{4}, \uparrow \\
0(0) \\
68(90) \\
8(10) \\
\end{array}$ & $\begin{array}{c}31.5 \pm 5.6 \\
15(5) \\
282(91) \\
13(4) \\
\end{array}$ \\
\hline $\begin{array}{l}\text { ProQOL V-secondary traumatic stress } \\
\text { Average } \\
\text { High level, } \mathrm{n}(\%) \\
\text { Moderate level, } \mathrm{n}(\%) \\
\text { Low level, } \mathrm{n}(\%) \\
\end{array}$ & $\begin{array}{c}28.5 \pm 4.6^{\dagger}: \mp \\
5(3) \\
151(94) \\
4(3)\end{array}$ & $\begin{array}{c}28.8 \pm 6.1^{*}: \neq \\
2(3) \\
61(82) \\
11(15)\end{array}$ & $\begin{array}{c}26.7 \pm 3.9^{*}, \uparrow \\
1(1) \\
65(86) \\
10(13)\end{array}$ & $\begin{array}{c}28.1 \pm 4.9 \\
8(3) \\
277(89) \\
25(8) \\
\end{array}$ \\
\hline $\begin{array}{l}\text { ProQOL V-compassion satiffaction } \\
\text { Average } \pm \mathrm{SD} \\
\text { High level, } \mathrm{n}(\%) \\
\text { Moderate level, } \mathrm{n}(\%) \\
\text { Low level, } \mathrm{n}(\%) \\
\end{array}$ & $\begin{array}{c}29.3 \pm 5.5^{\dagger} \div \\
4(3) \\
143(89) \\
13(8)\end{array}$ & $\begin{array}{c}30.5 \pm 6.8^{*}: \neq \\
5(7) \\
64(84) \\
5(7)\end{array}$ & $\begin{array}{c}32.7 \pm 5.4^{4}: \uparrow \\
1(1) \\
73(96) \\
2(3)\end{array}$ & $\begin{array}{c}30.4 \pm 6.0 \\
11(4) \\
280(90) \\
19(6)\end{array}$ \\
\hline
\end{tabular}

*: significantly different from Adult intensive care unit, $\dagger:$ significantly different from Adult/pediatric intensive care unit †:significantly different from pediatric intensive care unit,

\section{Figure 4}

Severity of BOS, STS and CS This figure shows the distribution of Severity of BOS, STS and CS for each intensive care unit. 

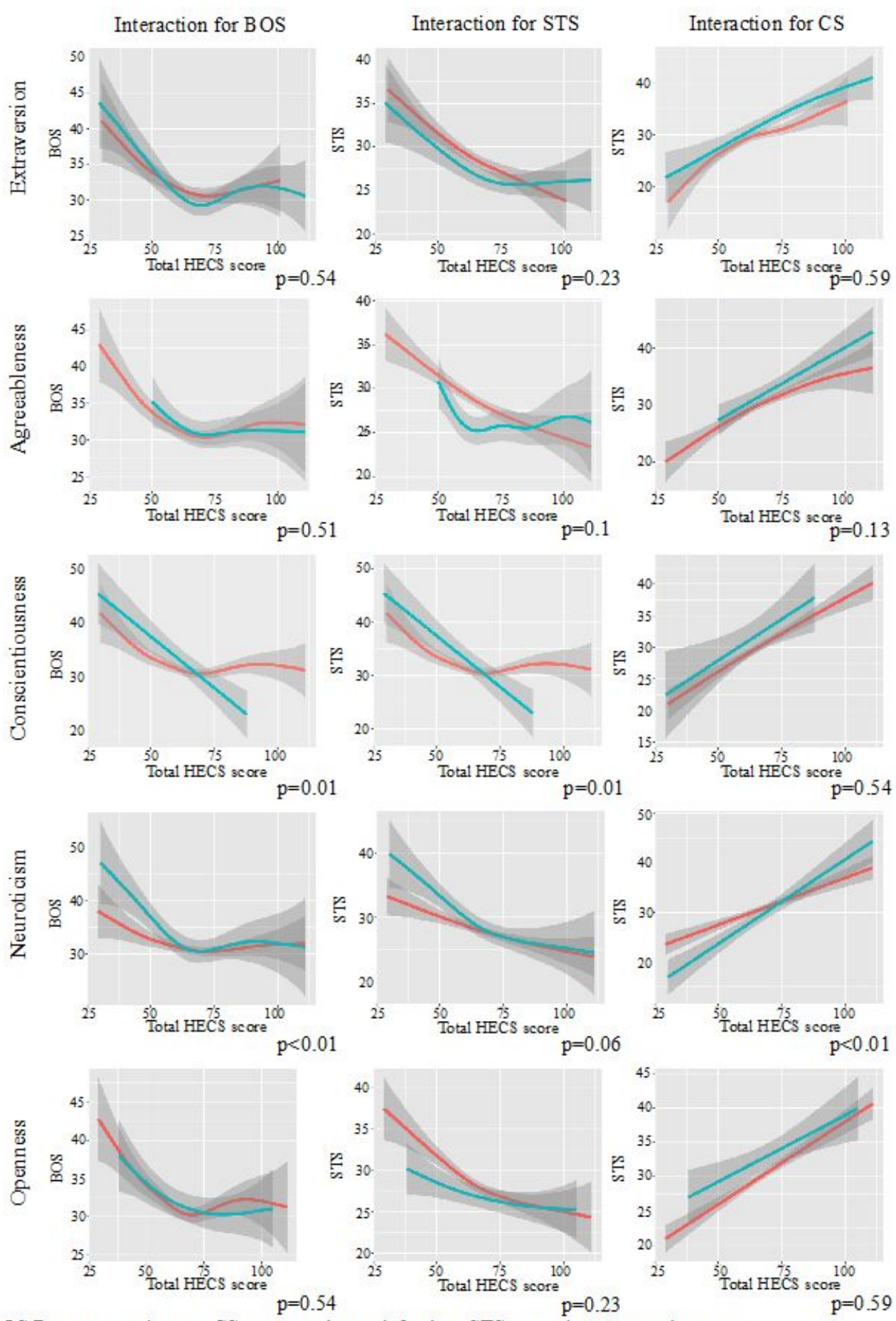

BOS:Bumout syndrome, CS: compassion satisfaction, STS: secondary traumatic stress We used age, sex, marital status, children, exercise habit and years of ICU experience as co-variate.

Representations of data shapes are provided in Supplementary File 3.

\section{Figure 5}

Interactions between personality traits and BOS, STS and CS This figure shows the interaction between high and low personality traits. We used age, sex, marital status, children, exercise habit and years of ICU experience as co-variates. 
A. Interaction for BOS

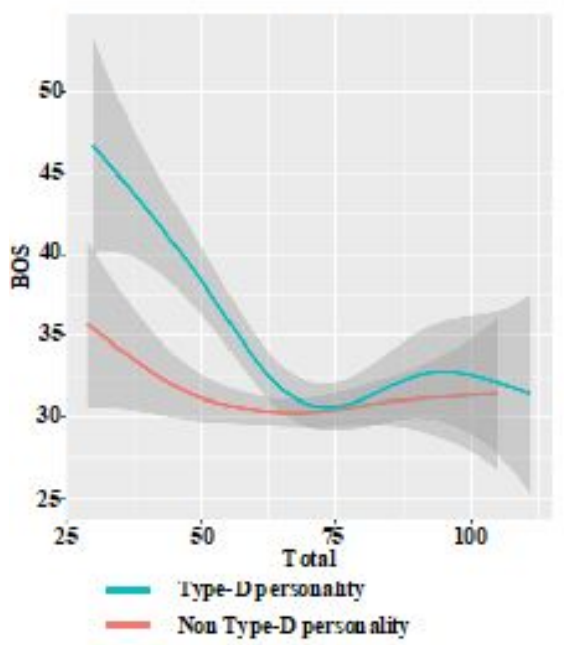

Interaction: $\mathbf{p}<0.01$

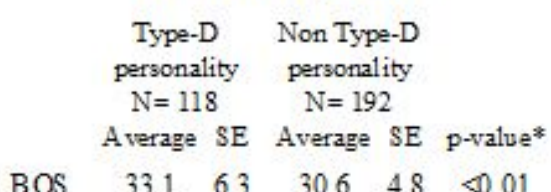

B. Interaction for STS

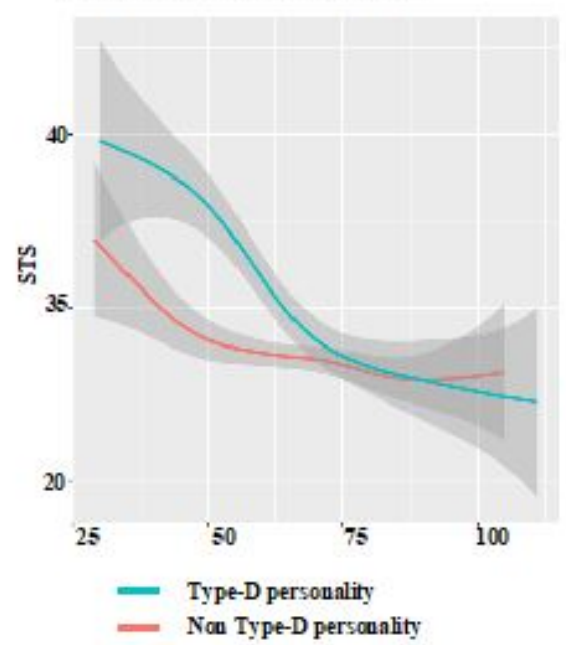

Interaction: $\mathbf{p}<0.01$

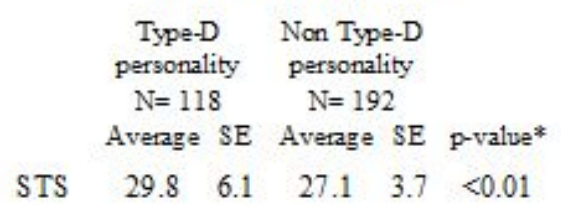

C. Interaction for CS

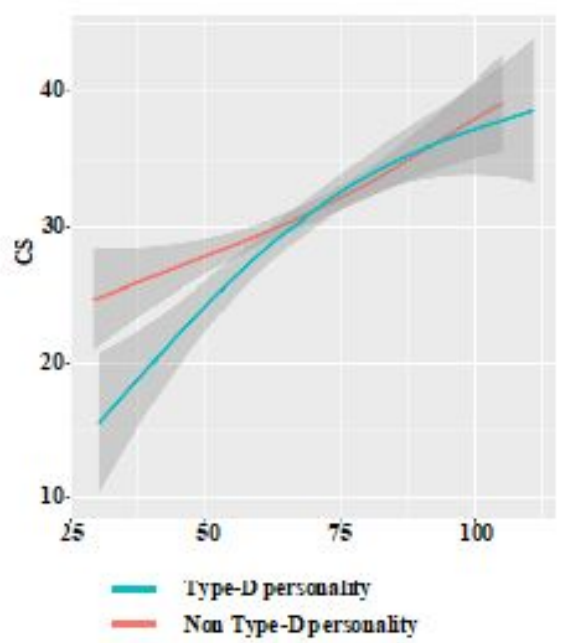

Interaction: $\mathrm{p}=0.29$

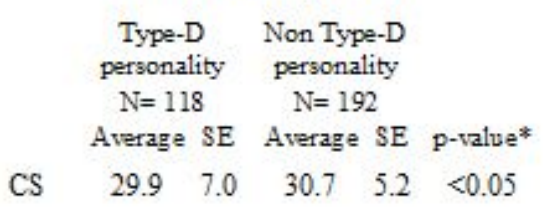

*p-value was obtained by GAM modeling. We us ed age, sex, marital status, children, exercise habit and years of ICU experience as co-variates.

\section{Figure 6}

Interactions between Type-D personality traits and BOS, STS and CS This figure shows the interaction between absence and presence of Type-D personality traits. We used age, sex, marital status, children, exercise habit and years of ICU experience as co-variates.

\section{Supplementary Files}

This is a list of supplementary files associated with this preprint. Click to download.

- OnlineDataSupplement1.pdf

- OnlineDataSupplement2.pdf

- OnlineDataSupplement3.pdf

- Table1.png

- Table2.jpg 